ASC Report No. 06/2008

\title{
Foreign Ownership Restrictions: A Numerical
} Approach

Bilgehan Karabay, Gernot Pulverer, Ewa Weinmüller 


\section{Most recent ASC Reports}

05/2008 Othmar Koch

Approximation of Meanfield Terms in MCTDHF Computations by $H$-Matrices

04/2008 Othmar Koch, Christian Lubich

Analysis and Time Integration of the Multi-Configuration Time-Dependent Hartree-Fock Equations in Electronic Dynamics

03/2008 Matthias Langer, Harald Woracek

Dependence of the Weyl Coefficient on Singular Interface Conditions

02/2008 Ansgar Jüngel, Daniel Matthes

A Review on Results for the Derrida-Lebowitz-Speer-Spohn Equation

01/2008 Christoph Erath, Stefan Funken, Dirk Praetorius

Adaptive Cell-centered Finite Volume Method

32/2007 Othmar Koch, Roswitha März, Dirk Praetorius, Ewa B. Weinmüller

Collocation for solving DAEs with Singularities

31/2007 Anton Baranov, Harald Woracek

Finite-Dimensional de Branges Subspaces Generated by Majorants

30/2007 Anton Baranov, Harald Woracek

Admissible Majorants for de Branges Spaces of Entire Functions

29/2007 Vyacheslav Pivovarchik, Harald Woracek

Shifted Hermite-Biehler Functions and their Applications

28/2007 Michael Kaltenbäck, Harald Woracek

Canonical Differential Equations of Hilbert-Schmidt Type

Institute for Analysis and Scientific Computing

Vienna University of Technology

Wiedner Hauptstraße 8-10

1040 Wien, Austria

E-Mail: admin@asc.tuwien.ac.at

WWW: http://www.asc.tuwien.ac.at

FAX: $\quad+43-1-58801-10196$

ISBN 978-3-902627-00-1

(C) Alle Rechte vorbehalten. Nachdruck nur mit Genehmigung des Autors. 


\title{
Foreign Ownership Restrictions: A Numerical Approach
}

\author{
Bilgehan Karabay,* Gernot Pulverer, and Ewa Weinmüller ${ }^{\dagger}$ \\ February 17, 2008
}

\begin{abstract}
In this paper, we analyze the reason behind the use of foreign ownership restrictions on inward Foreign Direct Investment (FDI). We extend the results developed in [38] by changing the condition on share distribution in the model. Due to this change, we are able to analyze the political economy aspect of this restrictive policy, i.e., we can study the effect of the host government's welfare preference on the optimal foreign ownership restriction. Since the analytical solution to the optimal share restriction policy cannot be specified in general, we use a numerical approach based on collocation to approximate the solution to the problem. Within this framework, under certain conditions, it turns out that the rent extractionefficiency trade-off is sharper the less the host government favors the local firm. We show that not only economic factors but also political factors play an important role in the determination of the foreign ownership restrictions.
\end{abstract}

Keywords: Ownership, Multinationals, Asymmetric Information, Regulation, Singular Boundary Value Problems in ODEs, Collocation Methods.

JEL classification: F23, L24, D82, P16, C63.

\section{Introduction}

Over the past few years, globalization has been one of the most intensely debated topics in international economics. The term 'globalization' is used to point out the growing economic interdependence between countries worldwide, through increasing volume and variety of cross border transactions in goods and services, free international capital flows, and more rapid and widespread diffusion of technology. Cross border transactions can take various forms such as International Trade, Foreign Direct Investment and Capital Market Flows. Our attention will be particularly focused on Foreign Direct Investment.

In recent years, there has been a worldwide surge in FDI flows. The tremendous increase in FDI is undoubtedly related to the globalization of the world economy. Over the past two decades, global flows of foreign direct investment have been recognized as a vital force in fostering economic growth. One interesting observation is the positive correlation between the level of inward FDI and economic performance, see [11]. On the one hand, FDI has the much desired potential to create jobs, transfer technology (including

\footnotetext{
*The Central Bank of the Republic of Turkey, Research and Monetary Policy Department, Istiklal cad., No. 10, Ulus, 06100, Ankara-TURKEY.

E-mail: bilgehan.karabay@tcmb.gov.tr.

${ }^{\dagger}$ Institute for Analysis and Scientific Computing, Vienna University of Technology, Wiedner Hauptstrasse 8-10, A-1040, Wien-Austria.

E-mail: gernotpulverer@gmail.com

E-mail: e.weinmueller@tuwien.ac.at.
} 
management skills), enhance export capacity and raise productivity, but on the other hand, some experts claim that the increased importance of FDI flows has eroded the ability of governments to make policies that restrict the activities of Multinational Firms (MNFs). Furthermore, complaints on abuses of monopoly power by MNFs are commonly mentioned. Nonetheless, most researchers seem to agree that the benefits of FDI exceed involved costs and disadvantages, cf. [49].

Many of the most important host countries have attracted large amounts of FDI while maintaining policy regimes at odds with MNFs' preferences, see [55]. Even though there is considerable evidence that most countries have followed a more positive stance towards FDI recently, restrictive policies are still in effect, cf. [30] and [31] for different types of restrictions. Most of the newly industrialized countries in Asia remain restrictive towards FDI. However, this has not prevented them from the high rates of FDI inflows. In Thailand, for example, the Alien Business Law of 1972, which was in effect until 1999, required every registered business to have a majority Thai ownership, see [28]. In 1999, a new act, entitled The Foreign Business Act, B.E. 2542, was passed. Even though the new act has liberalized some areas, it appears to be even more restrictive in others, see [22]. It is interesting to note that Thailand stands out as a successful country to attract export-oriented (efficiency-seeking) FDI, which is accepted as more sensitive to national FDI policy regime, cf. [34].

As many economists emphasize, FDI can only be explained and understood in the context of highly imperfect markets, see [26] and [13]. Most studies support the conclusion that the multinational firms are more productive than the local ones, cf. [37]. In addition, in case of the United States and Canada, respective literature includes [29] and [24]. For developing countries, this conclusion is supported by [10], [52], [45] and [33]. Moreover, productivity is often said to be increasingly firm specific, cf. [14]. This efficiency advantage explains MNFs' increased market power. To counter the monopoly power of the global firms, host countries have resorted to various measures of performance requirements, such as export-share requirement and domestic ownership requirement. In this work, we examine the motivation for the common use of the latter one.

The principal characteristic of FDI is the control over operations exercised by the investing entity over the investor entity. Ownership of equity enables firms to exercise control over operations. According to the property rights theory ([32], [36], [35]), changing the ownership structure of a firm, might create inefficiencies which can decrease the overall profitability of a project. ${ }^{1}$ If so, why do host countries still use ownership restrictions when other policy tools are available? The reason we propose is that FDI projects generate surpluses and information advantages of MNFs prevent host governments from capturing rents through direct taxation. Host governments' objectives in retaining rents may seem at odds with subsidies that are often offered to MNFs in the form of tax holidays and infrastructure provision. However, as many publications on time inconsistency problems in FDI policies have shown, these subsidies mainly pay for the sunk investments whose quasi-rents are subject to subsequent capture by host governments, see [53], [25] and [51].

In this paper, we extend the results from [38], where foreign ownership restrictions are analyzed. ${ }^{2}$ Restrictions on foreign ownership typically take the form of limiting the maximum ownership shares that non-residents can possess while investing in host countries, see [38] for a comprehensive literature review. Here, we change the condition on share distribution in such a way that ownership shares are distributed on the basis of the net profit rather than gross profit. Therefore, if a joint venture is considered, the partners do not pay their taxes individually, rather, the JV firm pays a single tax. The advantage of our new model compared to the one studied in [38] is that now optimal ownership restrictions depend on the particular form of the

\footnotetext{
${ }^{1}$ In [42], it is shown that ownership concentration is associated with superior performance: Concentrated foreign ownership improves economic performance, whereas domestic private ownership does not.

${ }^{2}$ We use the terms 'domestic ownership requirement' and 'foreign ownership restriction' interchangably.
} 
host government's welfare function. Therefore, the level of foreign ownership restrictions indicates the host government's welfare preference. Under this new specification, except for a case study identical to the one discussed in [38], we cannot provide an analytical solution to the problem. Nevertheless, from the analytical considerations we can derive an initial value problem for an ordinary differential equation (ODE) of second order. As a consequence, we can solve the problem numerically.

In our model, by combining moral hazard with adverse selection, we try to justify the claim that it is optimal to use foreign ownership restrictions. We assume that an advantageous investment opportunity is present in the host country. There is a pool of local firms and a single Multinational Firm that are willing to undertake the project. We further assume that the MNF is more productive and thus, can create more surplus than the local firms. The surplus the MNF can create consists of two parts. The first part depends on output and can be publicly observable. The second part is assumed to be independent of the output, like brand name effect, experience, etc., and cannot be publicly observable. It consists of two elements: Firm-specific advantage of the MNF and the MNF's effort. Hence, in order to benefit from its firm-specific advantage, the MNF needs to incur a costly unobservable effort. The host government intends to maximize its welfare which consists of the weighted average of its tax revenue and any possible local firm's profit. The weight given to the local firm's profit in the welfare reflects how much the government favors the local firm. The key feature of the model is the asymmetry of information between the host government and the MNF. The host government can observe neither the effort level nor the firm-specific advantage of the MNF. Likewise, it cannot observe the resulting surplus. On the other hand, if there is a joint venture partner, this partner can see this surplus amount, since it can observe the money flow into the firm, but it cannot observe the components of this surplus. ${ }^{3}$ Given these circumstances, we show that the host government can alleviate its information constraints by forcing a joint venture. ${ }^{4}$ Accordingly, the host government designs a mechanism that induces truth telling. We know from [48] and [17] that without loss of generality, we can restrict ourselves to such a truth-telling mechanism. For each report of the firm-specific advantage by the MNF, the host government assigns a maximum level of ownership the MNF can have, and the lump-sum tax/subsidy to the MNF and its joint venture partner, Local Firm (LF). In this mechanism, the game is played between the host government and the MNF. The LF plays a watchdog role and (indirectly) guarantees that the MNF does not lie in its report. This mechanism gives rise to truth telling since any possible collusion between the $\mathrm{LF}$ and the MNF is not sustainable.

The mathematical model arising from the above theory and whose solution we attempt to approximate, has the form of a nonlinear implicit scalar ordinary differential equation of second order which can be rewritten in a form of an implicit system of two differential equations (ODEs) of first order. In this case two boundary conditions need to be specified for the uniqueness of the solution. Here, the additional difficulty is that the linearized system whose solution we solve for during the Newton iteration, exhibits a singularity at the origin. Such singular systems are typically given in the following form:

$$
\begin{aligned}
& b^{\delta} z^{\prime}(b)=M(b) z(b)+b^{\delta} g(b), \quad b \in(0,1] \\
& R_{0} z(0)+R_{1} z(1)=\rho \\
& z \in C[0,1]
\end{aligned}
$$

where $\delta \geq 1, z$ is an $n$-dimensional real function, $M$ is a smooth $n \times n$ matrix, $R_{0}, R_{1}$ are constant $p \times n$ matrices, and $g$ is a smooth $n$-dimensional function. For $\delta=1$ the problem is called singular with a singularity of the first kind, for $\delta>1$ it is essentially singular (singularity of the second kind). For the singular problem

\footnotetext{
${ }^{3}$ This information structure is not crucial for our results. See section 4 in [38] for an alternative assumption.

${ }^{4}$ Imposing a joint venture is similar to ownership restrictions requiring the MNF to offer a minimum profit share to a domestic partner.
} 
with a continuous solution $z \in C[0,1]$, boundary conditions have to show a certain structure which depends on the eigenvalues of the matrix $M(0)$, see [20]. In general, $p<n$ holds and condition (1c) is equivalent to $n-p$ additional linearly independent conditions $z(0)$ must satisfy. These boundary conditions, augmented by (1b), are necessary and sufficient for the solution $z \in C[0,1]$ to be isolated and the problem (1) to be well-posed.

During the recent years a lot of effort has been put into the numerical analysis and code development for singular boundary value problems. The objective was to provide a sound theoretical basis and the implementation of an open domain MATLAB code for the numerical solution of BVPs with a singularity of the first kind, $\delta=1$. To compute the numerical solution of (1), we use collocation at an even ${ }^{5}$ number of collocation points spaced in the interior of a collocation interval. Our decision to use collocation was motivated by its advantageous convergence properties for (1). The convergence order is at least equal to the stage order of the method, while in the presence of a singularity other high order methods show order reductions and become inefficient cf. [5], [20] and [43]. The above convergence results mean that a collocation scheme with $s$ inner collocation points constitutes a high order basic solver - global error of the numerical solution decreases as $O\left(h^{s}\right)$ uniformly in $b$ when $h$ tends to zero - robust with respect to the singularity of the first kind. Here, we denote by $h$ the maximal stepsize in a (nonequidistant) grid.

In order to solve the ODE systems efficiently the meshes have to be adapted to the solution behavior. For singular problems, we aim at meshes which are not affected by the steep direction field, staying coarse also close to the singularity when the solution is smooth in that region. To design a mesh adaptation procedure, we need an efficient asymptotically correct a posteriori estimate for the error of the numerical solution. We propose to control the global error, because in the context of singular problems we observed that the values of the residual (a local error measure) are as a rule orders of magnitude larger than the global error. Thus, it often turns out that grids generated via the equidistribution of the residual are too fine and generate solutions whose global errors are dramatically smaller than the prescribed tolerance, which is inefficient. Our global error estimate was introduced in [4] and is based on the defect correction principle. We could show that for a collocation method of order $O\left(h^{s}\right)$, the error of the estimate (the difference between the exact global error and its estimate) is of order $O\left(h^{s+1}\right)$, see [5] and [43]. This asymptotically correct error estimate yields a reliable basis for an efficient mesh selection procedure. Our grid adaptation procedure results in grids which adequately reflect the solution behavior. Experimental evidence showing that our procedure works efficiently and dependably for singular problems can be found in [6], and a theoretical justification is given in [7].

Finally, the above algorithm has been implemented and provided as an open domain MATLAB code for fully implicit nonlinear problems with an error estimation routine and a grid selection strategy. This code, sbvp 1.0 for MaTLAB 6.0, has been published in 2002, see

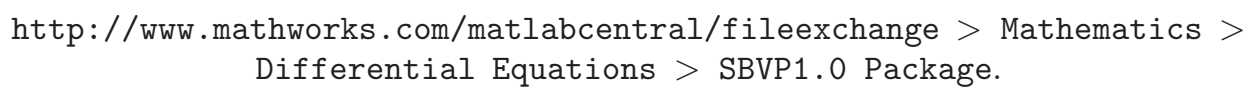

Comprehensive information on the program and its performance can be found in [3] and [6].

The code sbvp 1.0 was very well received by the scientific community and is broadly used in many areas of applications. However, sbvp 1.0, in its original version, was designed to solve only first order systems in explicit form, so that many important applications which we knew about, as the one which is the subject of this paper, were not in scope of the code. This was a strong motivation to implement a test version of a new MATLAB code bvpsuite addressing these additional requirements, cf. [40]. This code is designed to

\footnotetext{
${ }^{5}$ The even number of points is motivated by the technical details of the error estimation procedure.
} 
solve implicit systems of ODEs which may have variable order from zero to four,

$$
\begin{aligned}
& F\left(z^{(4)}(b), z^{(3)}(b), z^{\prime \prime}(b), z^{\prime}(b), z(b), b\right)=0, \quad b \in[0,1] \\
& R\left(z^{(3)}(0), z^{\prime \prime}(0), z^{\prime(3)}(1), z^{\prime \prime}(1), z^{\prime}(1), z(1)\right)=0 .
\end{aligned}
$$

In particular, algebraic constraints are also admitted. Moreover the code can cope with unknown parameters in a way that it is not necessary to introduce artificial differential equations for such parameters. Clearly, in this case additional boundary conditions have to be specified. This can be done not only at the boundary but also within the integration interval. The code can be applied to systems with both types of singularity and features appropriate routines for error estimation and grid adaptation, cf. [5] and [7]. The basic solver routine is still collocation at $s$ inner collocation points, the error estimate is now based on the more robust mesh halving, and the equidistribution of the global error is the basis for the grid adaptation routine.

Another important feature is that parameter-dependent problems are now in scope of the code since it has been augmented by an adaptive path-following strategy. The strategy is based on pseudo-arclength parametrization for the solution of parameter-dependent BVPs. We have formulated criteria which ensure successful application of this method for the computation of solution branches with turning points, for problems with singularities. In the present paper we were able to demonstrate that bvpsuite can be applied to solve problems of practical relevance exhibiting a singularity of the first kind.

The paper is organized as follows. In Section 2, we describe the main analytical properties of the model. The details of the numerical approach are specified in Section 3. In Section 4, we summarize and interpret the results. Finally, we give proofs of standard results in full detail.

\section{Model Setting and Analytical Results}

Model description relies heavily on the discussion from [38]. We consider a host country having an advantage for the production of a particular good. Either an MNF or LF can take advantage of this profitable investment opportunity. There is a pool of competitive local firms in the host country. The MNF has an advantage over these firms so that it can create a higher surplus than any other local firm. Hence, ceteris paribus, it is more efficient for the MNF to undertake the project. The surplus that the MNF can create has two parts: The first part, denoted by $\pi^{M N F}$, depends on output and hence is publicly observable and the second part depends on intangible assets such as experience, brand name, etc., and thus is publicly unobservable. The latter is a function of the MNF's firm-specific advantage $b$. To benefit from it, the MNF must exert an effort $e \in\{0\} \cup R^{+}$. Consequently, the realized unobservable profit takes the form of $e * b$. The effort cost is convex and has the form $e^{2} / 2$. The firm-specific advantage $b$ is assumed to be a random variable with the support $[\underline{b}, \bar{b}]$, where $0 \leq \underline{b}<\bar{b}$, with distribution function $F(b)$ and density function $f(b)$. On the other hand, the total surplus that any local firm can generate is equal to $\pi^{L F}<\pi^{M N F}{ }^{6}$

The MNF has two ways to enter the host market: It can either enter as a fully-owned firm or it can form a joint venture (JV) with one of the domestic firms. It is assumed that local firms do not have any bargaining power and play no role in determining ownership shares in a possible JV. ${ }^{7}$ It is also assumed that from the MNF's perspective, there is no advantage in having a local JV partner. ${ }^{8}$ Therefore, as long as there is no

\footnotetext{
${ }^{6}$ We assume that due to its easy access to world markets, the MNF can access inputs at a lower cost than the local firms thus can create more surplus in the observable portion of the profit.

${ }^{7}$ It follows directly from an assumption that local partners are drawn from a supply of homogeneous and competitive firms.

${ }^{8}$ The underlying assumption here is that having a local JV partner does not increase the total surplus. Alternatively, rather than assuming $\pi^{L F}<\pi^{M N F}$, one may assume that a possible JV can create more surplus. Then all the results follow.
} 
outside intervention, the MNF chooses to form a fully-owned firm.

At the time of entering the domestic market, the MNF observes the actual realization of $b$. This information is private and cannot be observed by the government of the host country. In case of a JV, the local JV partner can observe the realized surplus $e * b$, but not the individual values of $e$ or $b$. Hence, the effort level is observable by neither the host government nor any possible local JV partner. On the other hand, once the surplus is realized, it is assumed that the local firm can claim (without charges) its government determined share by appealing to a court. ${ }^{9}$

The host government intends to maximize its welfare which consists of the weighted average of its tax revenue and any possible profit made by the local firm. For simplicity, we assume that the resulting product is sold to a third country in order to ignore consumer effects and keep the analysis well focused. ${ }^{10}$ Therefore, we consider export-oriented (efficiency-seeking) FDI.

There are two policy tools the host government can use to regulate the MNF: Lump-sum tax/subsidy and domestic ownership requirement. Focusing on linear incentive contracts is justified by their robustness to uncertainty, cf. [46]. If the host government decides to use ownership requirement, it picks the local partner for the JV randomly. ${ }^{11}$ In contrast to [38], we assume that if there exists a joint venture, then the partners do not pay different taxes - a single tax is paid by the firm as a whole. It will turn out that this slight change in the problem setting creates quite a difficulty in the analytical solution.

Assumption 1. $\pi^{i} \geqslant 0$, where $i=\{M N F, L F\}$.

Assumption 2. Local firms are liquidity constrained.

The first condition ensures that the project is profitable. The second condition simply means that due to imperfect capital markets, local firms cannot borrow from outside, and are thus constrained by their current payoffs.

The timing of the game can be summarized in the following way:

1. The MNF learns the actual value of the firm-specific advantage $b$.

2. The host government designs a mechanism that prescribes a lump-sum tax/subsidy and ownership restriction for the MNF's each report of $b$.

3. The MNF decides whether to enter the market or not. If it decides not to enter, the game ends here. Otherwise, the game continues.

4. The MNF announces its $b$ to the host government and its ownership share and tax/subsidy are determined by the mechanism from step 2 .

5. The MNF chooses its effort level.

6. Production is carried out and respective payoffs are realized.

\footnotetext{
${ }^{9}$ Introducing a small cost for appealing to court would not change any of the results other than shifting rents from the host government to the MNF in the amount of this cost.

${ }^{10} \mathrm{We}$ can easily incorporate consumer effects into the analysis, see section 4 in [38]. This will not change our results.

${ }^{11}$ It would be possible to analyze the game between the local firms and the host government for the selection of the JV partner. However, this question is beyond the scope of the paper.
} 


\subsection{Optimal Mechanism}

In this model, a mechanism that induces truthful revelation is considered. An optimal mechanism is represented by the following four tuple:

$$
M \equiv\left\{\alpha(b), T^{L F}(b), T^{J V}(b), \gamma(b)\right\}
$$

where $\alpha(b) \in[0,1]$ is the probability that the host government allows the MNF to take part in the production process, $T^{L F}(b)$ is the payment to be made to the host government by the LF as a function of the reported value of $b$ when the MNF is not allowed to operate in the host market, $T^{J V}(b)$ is the payment to be made to the host government by the JV as a function of the reported value of $b$ when the MNF is allowed to operate in the host market. Finally, $\gamma(b) \in[0,1]$ represents the maximum ownership that the MNF can have if it is allowed to operate.

Given a mechanism $M$, let us denote by $\Pi^{M N F}(\widehat{b}, b)$ the profit made by the MNF of type $b$ if it reports type $\widehat{b}$. Clearly,

$$
\Pi^{M N F}(\widehat{b}, b)=\alpha(\widehat{b}) \gamma(\widehat{b})\left(\pi^{M N F}+e b-T^{J V}(\widehat{b})\right)-\alpha(\widehat{b}) \frac{e^{2}}{2} .
$$

Note that in the above profit function, the MNF's realized effort cost cannot be observed by other agents. Therefore, the only incentive for the MNF to incur effort is the ownership shares. The optimal effort level, given the ownership shares, can be found by

$$
\max _{e} \alpha(\widehat{b}) \gamma(\widehat{b})\left(\pi^{M N F}+e b-T^{J V}(\widehat{b})\right)-\alpha(\widehat{b}) \frac{e^{2}}{2} \Rightarrow e=\gamma(\widehat{b}) b .
$$

Thus, one can rewrite equation (2) as

$$
\Pi^{M N F}(\widehat{b}, b)=\alpha(\widehat{b}) \gamma(\widehat{b})\left(\pi^{M N F}+\gamma(\widehat{b}) b^{2}-T^{J V}(\widehat{b})\right)-\alpha(\widehat{b}) \frac{(\gamma(\widehat{b}) b)^{2}}{2} .
$$

The requirement of truthful reporting, incentive compatibility, means

$$
\Pi^{M N F}(b, b) \geqslant \Pi^{M N F}(\widehat{b}, b)
$$

for all $b, \widehat{b} \in[\underline{b}, \bar{b}]$. Likewise, we conclude $\Pi^{M N F}(b, b) \geqslant 0$ for all $b$, by imposing the condition of the individual rationality.

Since the local firm's net profit is known after the host government has obtained the truthful report of $b$ from the MNF, it can be written in the form

$$
\begin{aligned}
\Pi^{L F}(b)= & (1-\alpha(b))\left(\pi^{L F}-T^{L F}(b)\right)+ \\
& \alpha(b)(1-\gamma(b))\left(\pi^{M N F}+\gamma(b) b^{2}-T^{J V}(b)\right) .
\end{aligned}
$$

The expected welfare of the government from the truthful mechanism is given by

$$
W=\int_{\underline{b}}^{\bar{b}}\left(\phi_{1} E(T)+\phi_{2} \Pi^{L F}(b)\right) d F(b),
$$

where $E(T)=(1-\alpha(b)) T^{L F}(b)+\alpha(b) T^{J V}(b), \Pi^{L F}(b)$ is the local firm's net profit, after tax, $\phi_{1}$ is the weight given to the tax revenue and $\phi_{2}$ is the weight given to the local firm's net profit in the welfare function. Here, we set $\phi_{1} \geq \phi_{2}$. This assumption implies that the host government values a dollar from a tax revenue at 
least as high as a dollar in the hands of a local firm. We now introduce $\phi:=\frac{\phi_{2}}{\phi_{1}} \leq 1$, and with this notation we can rewrite (6),

$$
W=\int_{\underline{b}}^{\bar{b}}\left(E(T)+\phi \Pi^{L F}(b)\right) d F(b) .
$$

In order to characterize the optimal mechanism, we make additional assumptions.

Assumption 3. For the distribution function $F(b)$,

$$
(1-F(b)) / f(b)
$$

is decreasing as a function of $b$.

Examples of distributions verifying the monotone hazard rate conditions include the uniform, the exponential, the normal, the extreme value, the logistic and the Laplace distributions. A more complete list is provided in [8]. A sufficient condition for the above assumption to hold is that the function $\log f(b)$ is concave on $[\underline{b}, \bar{b}]$.

Assumption 4. If the MNF does not pay the government determined share to the local JV partner, the LF can appeal to a court. In the court, the LF can prove the true value of $e * b$ and consequently, receive its true share from the project.

It is further assumed that the JV partners cannot form a sustainable collusion. In a sustainable collusion, the local firm has to guarantee that it will not appeal to a court when the project is completed. By disregarding collusion, we implicitly assume that it is not possible to design a binding contract that prevents the local firm to appeal to a court. ${ }^{12}$

Lemma 1 A mechanism $M$ is incentive compatible iff

$$
\frac{d \Pi^{M N F}(b)}{d b}=\alpha(b) \gamma(b)^{2} b
$$

almost everywhere, with $\Pi^{M N F}(b)=\max _{\widehat{b} \in[\underline{b}, \bar{b}]} \Pi^{M N F}(\widehat{b}, b)$ and the function $\alpha(b) \gamma(b)^{2}$ is non-decreasing.

Proof. See Appendix.

Assumption 5. $\pi^{M N F}-\pi^{L F}>0$ is big enough such that $\alpha(b)=1, \forall b{ }^{13}$

Lemma 2 In any feasible mechanism, the welfare function of the host government is given by

$$
W=\int_{\underline{b}}^{\bar{b}}\left(\pi^{M N F}+\left(\frac{1+\phi(1-\gamma(b))}{2} \gamma(b) b^{2}\right)-\frac{1-\phi(1-\gamma(b))}{\gamma(b)}\left(\int_{\underline{b}}^{b} \gamma^{2}(\widetilde{b}) \tilde{b} \widetilde{d}\right)\right) d F(b) .
$$

Proof. See Appendix.

Note that since $\alpha(b) \equiv 1$ by assumption 5 , the monotonicity condition from Lemma 1 implies that $\gamma(b)$ has to be non-decreasing.

\footnotetext{
${ }^{12}$ See section 5.2 in [38] for the case of collusion.

${ }^{13}$ This is a restrictive but a necessary assumption to solve the model numerically. It means that the host government would always allow the MNF to operate in the host market.
} 


\subsection{Case $\phi=1$}

Let us first consider the simple case $\phi=1$.

Proposition 3 Let $\phi=1$ and let Assumptions $1-5$ hold. Then the optimal mechanism is specified by the following values:

$$
\begin{aligned}
T^{L F}(b) & =T^{L F}=\pi^{L F} \\
T^{J V}(b) & =\pi^{M N F}+\frac{\gamma(b) b^{2}}{2}-\frac{1}{\alpha(b) \gamma(b)} \int_{\underline{b}}^{b} \alpha(\widetilde{b}) \gamma(\widetilde{b})^{2} \widetilde{b} d \widetilde{b} \\
\gamma(b) & =\frac{b}{2\left(\frac{1-F(b)}{f(b)}\right)+b} .
\end{aligned}
$$

Proof: See Appendix.

There are few comments that should be made concerning the optimal mechanism specified above. ${ }^{14}$ The mechanism design problem arises only between the MNF and the host government. The LF plays only a watchdog role. Furthermore, the rent given to the MNF for truthful revelation is proportional to its share in the JV. That means, when the host government chooses the MNF's ownership share, it faces a trade-off: Higher share means greater efficiency but also higher information rents for the MNF. Given this trade-off, we can see that the share of the MNF is higher, the higher is the firm-specific advantage. Also, the tax that is collected from the JV firm increases as the firm-specific advantage increases. It is interesting to note that the host government gives information rent to the LF even though it plays the game with the MNF only. This is due to the set-up of the model. When the MNF is allowed in the host market, only a single tax can be collected from the JV firm. In other words, the host government cannot tax the MNF and the LF separately. ${ }^{15}$ (In [38], separate taxation is allowed.)

\subsection{Case $\phi<1$}

For $\phi=1$ we were able to derive the analytical solution for the optimal mechanism. When $\phi<1$, the coefficient of the last term in (9) is a function of $\gamma$ and we cannot use integration by parts. Therefore, we have to approximate the solution of the model numerically. From now on we assume a particular distribution function for the firm-specific advantage of the MNF.

Assumption 6. $b \sim$ Uniform $(0,1)$. Hence, $F(b)=b$ and $f(b)=1$.

Now, given Assumption 6, equation (9) becomes

$$
W=\pi^{M N F}+\int_{0}^{1}\left(\left(\frac{\gamma(b) b^{2}}{2}\right)(1+\phi(1-\gamma(b)))-\left(\frac{1-\phi(1-\gamma(b))}{\gamma(b)}\right) \int_{0}^{b} \gamma^{2}(\widetilde{b}) \widetilde{b} d \tilde{b}\right) d b .
$$

With the following change of variables

$$
z(b)=\int_{0}^{b} \gamma^{2}(\tilde{b}) \tilde{b} d \tilde{b}
$$

\footnotetext{
${ }^{14}$ See [38] for a more detailed analysis of the optimal mechanism.

${ }^{15}$ The taxation of joint ventures is a delicate issue and different countries can follow different rules. However, in general, if the firm is considered as a contractual joint venture, then each partner pays his/her own income tax, whereas, if it is considered as a corporate joint venture, the firm as a whole pays income tax to the government. In this paper, we have a corporate joint venture in mind.
} 
it follows immediately that

$$
\begin{aligned}
z^{\prime}(b) & =\gamma^{2}(b) b \\
\gamma(b) & =\frac{\sqrt{z^{\prime}(b)}}{\sqrt{b}}
\end{aligned}
$$

Now we have

$$
\begin{aligned}
W & =\pi^{M N F}+\int_{0}^{1}\left(\left(\frac{b^{3 / 2} \sqrt{z^{\prime}(b)}}{2}\right)\left(1+\phi\left(1-\frac{\sqrt{z^{\prime}(b)}}{\sqrt{b}}\right)\right)-\left(\frac{1-\phi\left(1-\frac{\sqrt{z^{\prime}(b)}}{\sqrt{b}}\right)}{\frac{\sqrt{z^{\prime}(b)}}{\sqrt{b}}}\right) z(b)\right) d b \\
& =: \pi^{M N F}+\int_{0}^{1} \widetilde{W}\left(b, z(b), z^{\prime}(b)\right) d b .
\end{aligned}
$$

In order to obtain the optimal $\gamma$ we again use calculus of variations and maximize $W$ with respect to $z$. The Euler-Lagrange equation,

$$
\frac{\partial \widetilde{W}}{\partial z}-\frac{d}{d b}\left(\frac{\partial \widetilde{W}}{\partial z^{\prime}}\right)=0
$$

yields

$$
-(1-\phi) \frac{\sqrt{b}}{\sqrt{z^{\prime}(b)}}-\phi-\frac{d}{d b}\left(\frac{(1+\phi) b^{3 / 2}}{4 \sqrt{z^{\prime}(b)}}-\frac{\phi b}{2}+\frac{(1-\phi) \sqrt{b} z(b)}{2\left(z^{\prime}(b)\right)^{3 / 2}}\right)=0 .
$$

Rearranging terms in the last equation results in an implicit nonlinear ordinary differential equation of second order exhibiting singular coefficients at $b=0$,

$$
z^{\prime \prime}(b)\left(6(1-\phi) z(b)+(1+\phi) b z^{\prime}(b)\right)-(15-9 \phi)\left(z^{\prime}(b)\right)^{2}-\frac{2(1-\phi) z(b) z^{\prime}(b)}{b}-\frac{4 \phi z^{\prime}(b)^{5 / 2}}{\sqrt{b}}=0, b \in(0,1]
$$

For the numerical solution we now need to specify two initial/boundary conditions. From the practical point of view, it would be natural to use two initial conditions, $z(0)=0$ and $z^{\prime}(0)=0$, which follow directly from the definition of $z$. Unfortunately, these conditions are not posed correctly to specify a well-posed initial value problem and therefore, any standard numerical procedure will not be able to successfully integrate the problem.

The idea now is to find out if the singularity in (12) is of the first or of the second type, and then use the framework for singular ODEs to specify correct initial/boundary conditions resulting in a well-posed problem which can be solved numerically, see [20], [56] and [57]. It will turn out that the above ODE is singular with the singularity of the first kind and that we necessarily need to specify a homogenous initial condition $z(0)=0$ and a terminal condition which may have the form $R\left(z(1), z^{\prime}(1)\right)=0$. Unfortunately, from the available model data it is not possible to specify $R$, so we are left to try different options. Nevertheless, the numerical results will show that solution behavior does not depend on the choice of the terminal condition, and consequently, numerical experiments will provide enough meaningful information on the optimal mechanism.

In order to investigate the structure of (12) we have to study the linearized problem. Consider the nonlinear boundary value problem

$$
\begin{aligned}
& f\left(z^{\prime \prime}(b), z^{\prime}(b), z(b), b\right)=0, \quad b \in(0,1] \\
& R\left(z^{\prime}(0), z^{\prime}(1), z(0), z(1)\right)=0
\end{aligned}
$$


where $z \in \mathbb{R}^{n}$, and $f \in \mathbb{R}^{n}$ and $R \in \mathbb{R}^{2 n}$ are given functions defined on proper domains. Let us assume that a solution of (13), $z \in C^{1}[0,1]$, exists. Then, the problem (13) is well-posed and the solution $z$ is isolated when the following linearized problem with homogeneous data has only the trivial solution $v(b) \equiv 0$ :

$$
\begin{aligned}
& \left.\frac{\partial f\left(z^{\prime \prime}(b), z^{\prime}(b), z(b), b\right)}{\partial z^{\prime \prime}(b)} v^{\prime \prime}(b)+\frac{\partial f\left(z^{\prime \prime}(b), z^{\prime}(b), z(b), b\right)}{\partial z^{\prime}(b)} v^{\prime}(b)+\frac{\partial f\left(z^{\prime \prime}(b), z^{\prime}(b), z(b), b\right)}{\partial z(b)} v(b)=0, b \in(0,1],(11), z(1)\right) \\
& \frac{\partial R\left(z^{\prime}(0), z^{\prime}(1), z(0), z(1)\right)}{\partial z^{\prime}(0)} v^{\prime}(0)+\frac{\partial R\left(z^{\prime}(0), z^{\prime}(1), z(0), z(1)\right)}{\partial z^{\prime}(1)} v^{\prime}(1)+ \\
& \quad \frac{\partial R\left(z^{\prime}(0), z^{\prime}(1), z(0), z(1)\right)}{\partial z(0)} v(0)+\frac{\partial R\left(z^{\prime}(0), z^{\prime}(1), z(0), z(1)\right)}{\partial z(1)} v(1)=0
\end{aligned}
$$

In our case $(14 \mathrm{a})$ becomes

$$
\begin{aligned}
& \left(6(1-\phi) z(b)+(1+\phi) b z^{\prime}(b)\right) v^{\prime \prime}(b)+6 z^{\prime \prime}(b)(1-\phi) v(b)+z^{\prime \prime}(b)(1+\phi) b v^{\prime}(b)-2(15-9 \phi) z^{\prime}(b) v^{\prime}(b)- \\
& \frac{2(1-\phi) z(b)}{b} v^{\prime}(b)-\frac{2(1-\phi) z^{\prime}(b)}{b} v(b)-\frac{20 \phi z^{\prime}(b)^{3 / 2}}{2 \sqrt{b}} v^{\prime}(b)=0, \quad b \in(0,1] .
\end{aligned}
$$

Now, we collect the terms of the same order and obtain

$$
\begin{aligned}
& \left(6(1-\phi) z(b)+(1+\phi) b z^{\prime}(b)\right) v^{\prime \prime}(b)+ \\
& \left(z^{\prime \prime}(b)(1+\phi) b-(30-18 \phi) z^{\prime}(b)-\frac{2(1-\phi) z(b)}{b}-\frac{10 \phi z^{\prime}(b)^{3 / 2}}{\sqrt{b}}\right) v^{\prime}(b)+ \\
& \left(6 z^{\prime \prime}(b)(1-\phi)-\frac{2(1-\phi) z^{\prime}(b)}{b}\right) v(b)=0, \quad b \in(0,1] .
\end{aligned}
$$

We assume that $z \in C^{4}[0,1]$ and use Taylor expansion for $z(b)$ around $b=0$ to obtain $z(b)=z(0)+b z^{\prime}(0)+$ $O\left(b^{2}\right)=\frac{1}{2} b^{2} z^{\prime \prime}(\xi(b))$, where $\xi \in(0, b)$. Since only the local behavior at the singular point $b=0$ is crucial for the structure of boundary conditions, we assume from now on that $b \approx \xi \approx 0$. Therefore,

$$
z(b)=\frac{1}{2} b^{2} z^{\prime \prime}(\xi), z^{\prime}(b) \approx b z^{\prime \prime}(\xi), z^{\prime \prime}(b) \approx z^{\prime \prime}(\xi) .
$$

After substituting (16) into (15) we have

$$
v^{\prime \prime}(b)-\frac{a_{1}}{b} v^{\prime}(b)-\frac{a_{0}}{b^{2}} v(b)=0, \quad b \in(0,1],
$$

where

$$
a_{1}=\frac{5\left(3-2 \phi+\phi \sqrt{z^{\prime \prime}(\xi)}\right)}{2-\phi}, \quad a_{0}=-\frac{2(1-\phi)}{2-\phi} .
$$

Finally, we use the Euler transformation $u(b):=\left(v(b), b v^{\prime}(b)\right)^{T}$ to derive the related first order system with a singularity of the first kind, cf. (1a),

$$
u^{\prime}(b)=\frac{1}{b} M(b) u(b), \quad b \in(0,1],
$$

where

$$
M=\left(\begin{array}{cc}
0 & 1 \\
a_{0} & 1+a_{1}
\end{array}\right)=\left(\begin{array}{cc}
0 & 1 \\
-\frac{2(1-\phi)}{2-\phi} & 1+\frac{5\left(3-2 \phi+\phi \sqrt{z^{\prime \prime}(\xi)}\right)}{2-\phi}
\end{array}\right) .
$$

According to the theory, see [20], [56], we now need to find the eigenvalues of $M(0)$ which will provide correct 
boundary conditions necessary and sufficient for the boundary value problem to become well-posed. From

$$
\begin{aligned}
& |M-\lambda I|=\left|\begin{array}{cc}
-\lambda & 1 \\
-\frac{2(1-\phi)}{2-\phi} & 1+\frac{5\left(3-2 \phi+\phi \sqrt{z^{\prime \prime}(\xi)}\right)}{2-\phi}-\lambda
\end{array}\right|= \\
& \lambda^{2}-\lambda\left(1+\frac{5\left(3-2 \phi+\phi \sqrt{z^{\prime \prime}(\xi)}\right)}{2-\phi}\right)+\frac{2(1-\phi)}{2-\phi}=0
\end{aligned}
$$

we find

$$
\lambda_{1,2}=\frac{1}{2}+\frac{5\left(3-2 \phi+\phi \sqrt{z^{\prime \prime}(\xi)}\right)}{2(2-\phi)} \pm \sqrt{\left(\frac{1}{2}+\frac{5\left(3-2 \phi+\phi \sqrt{z^{\prime \prime}(\xi)}\right)}{2(2-\phi)}\right)^{2}-\frac{2(1-\phi)}{2-\phi}}
$$

or equivalently,

$$
\begin{aligned}
\lambda_{1,2}= & \frac{1}{2}+\frac{5\left(3-2 \phi+\phi \sqrt{z^{\prime \prime}(\xi)}\right)}{2(2-\phi)} \pm \\
& \sqrt{\frac{353-384 \phi+140 \phi^{2}+190 \phi \sqrt{z^{\prime \prime}(\xi)}-120 \phi^{2} \sqrt{z^{\prime \prime}(\xi)}+25 \phi^{2} z^{\prime \prime}(\xi)}{4(2-\phi)^{2}}} .
\end{aligned}
$$

Proposition 4 Let $z^{\prime \prime}(\xi) \geq 0$. Then $\lambda_{1,2} \in \mathbb{R}$ and $\lambda_{1}>0, \lambda_{2}<0$.

Proof: See Appendix.

Due to the above result, since $\lambda_{2}<0$, one of the boundary conditions needs to be posed at $b=0$ and has the form $z(0)=0$, cf. (1c) and the related remarks on pages 3 and 5. Because $\lambda_{1}>0$ the related second boundary condition has to be specified at $b=1$, see (1b). Consequently, the problem would be not well-posed with both boundary conditions given at the left endpoint of the interval of integration.

Unfortunately, we cannot impose a condition on the right boundary following as a natural implication from the model data. Nevertheless, numerical experiments still provide valuable information on how the solution behaves for different hypothetic values of $z^{\prime}(1)$.

\section{$3 \quad$ Numerical Results}

We have seen in the previous section that we need to solve a boundary value problem with a singularity of the first kind for a second order ODE of the form,

$$
\begin{aligned}
& F\left(z^{\prime \prime}(b), z^{\prime}(b), z(b), b\right)=0, \quad t \in(0,1], \\
& z(0)=0, \quad z^{\prime}(1)=\zeta .
\end{aligned}
$$

We assume that the analytical solution $z$ is appropriately smooth and attempt to solve this problem numerically using the collocation method implemented in our Matlab code bvpsuite. This code is a new version of the general purpose MATLAB code sbvp, cf. [6] and [40], which has already been successfully applied to a variety of problems, see for example [4], [12], [40], and [41]. Collocation is a widely used and well-studied standard solution method for two-point boundary value problems, see for example [1] and the references therein. It also proved robust in case of singular boundary value problems.

The code is designed to solve systems of differential equations whose order may vary between four and zero, which means that algebraic constrains which do not involve derivatives are also admitted. Moreover, the problem can be given in a fully implicit form, 


$$
\begin{aligned}
& F\left(z^{(4)}(b), z^{(3)}(b), z^{\prime \prime}(b), z^{\prime}(b), z(b), b\right)=0, \quad b \in[0,1], \\
& R\left(z^{(3)}(0), z^{\prime \prime}(0), z^{\prime}(0), z(0), z^{(3)}(1), z^{\prime \prime}(1), z^{\prime}(1), z(1)\right)=0 .
\end{aligned}
$$

The program can also cope with free parameters, $\lambda_{1}, \lambda_{2}, \ldots, \lambda_{k}$, which will be computed along with the numerical approximation for $z$,

$$
\begin{aligned}
& F\left(z^{(4)}(b), z^{(3)}(b), z^{\prime \prime}(b), z^{\prime}(b), z(b), b, \lambda_{1}, \lambda_{2}, \ldots, \lambda_{k}\right)=0, \quad b \in[0,1], \\
& R_{\text {aug }}\left(z^{(3)}(0), z^{\prime \prime}(0), z^{\prime}(0), z(0), z^{(3)}(1), z^{\prime \prime}(1), z^{\prime}(1), z(1)\right)=0 .
\end{aligned}
$$

provided that the boundary conditions $R_{\text {aug }}$ include $k$ additional requirements to be satisfied by $z$.

The numerical approximation defined by collocation is computed as follows: On a mesh,

$$
\Delta:=\left\{b_{i}: i=0, \ldots, N\right\}, \quad 0=b_{0}<b_{1} \cdots<b_{N}=1,
$$

we approximate the analytical solution by a piecewise defined collocating function

$$
p(b):=p_{i}(b), \quad b \in\left[b_{i}, b_{i+1}\right], \quad i=0, \ldots, N-1,
$$

where $p_{i}$ are polynomials of maximal degree $s-1+q, 0 \leq q \leq 4$. In order to determine coefficients in the ansatz for $p$, we require that $p \in C^{q-1}[0,1]$ if the order of the underlying differential equation is $q$, each $p_{i}$ solves the system (17a) at $s$ collocation points

$$
\left\{\beta_{i, j}=\beta_{i}+\rho_{j}\left(\beta_{i+1}-\beta_{i}\right), i=0, \ldots, N-1, j=1, \ldots, s\right\}, \quad 0<\rho_{1}<\cdots<\rho_{s}<1,
$$

and $p_{0}$ and $p_{N}$ satisfy the associated boundary conditions (17b). Classical theory, cf. [1], predicts that for appropriately smooth solution $z$ the convergence order for the global error of the method is at least $O\left(h^{s}\right)$, where $h$ is the maximal stepsize, $h:=\max _{i}\left(b_{i+1}-b_{i}\right)$. More precisely, $\|p-z\|_{\infty}=O\left(h^{s}\right)$ holds, uniformly in $b$. Analogous results hold for the first and second order singular ODEs with a singularity of the first kind, cf. [19], [43], [58]. For certain choices of the collocation points the so-called superconvergence order can be observed. In case of Gaussian points this means that the approximation is exceptionally precise at the meshpoints $b_{i},\left\|p\left(b_{i}\right)-z\left(b_{i}\right)\right\|_{\infty}=O\left(h^{2 s}\right)$.

To make the computations more efficient, we additionally use an adaptive mesh selection strategy based on a posteriori estimate for the global error of the collocation solution. We use a classical error estimate based on mesh halving. In this approach, we compute the collocation solution $p_{\Delta}(b)$ on a mesh $\Delta$. Subsequently, we choose a second mesh $\Delta_{2}$ where in every interval $\left[b_{i}, b_{i+1}\right]$ of $\Delta$ we insert two subintervals of equal length. On this new mesh, we compute the numerical solution using the same collocation scheme to obtain the collocating function $p_{\Delta_{2}}(b)$. Using these two quantities, we define

$$
\mathcal{E}(b):=\frac{2^{s}}{1-2^{s}}\left(p_{\Delta_{2}}(b)-p_{\Delta}(b)\right)
$$

as an error estimate for the approximation $p_{\Delta}(b)$. Assume that the global error $\delta(b):=p_{\Delta}(b)-z(b)$ of the collocation solution can be expressed in terms of the principal error function $\tilde{e}(b)$,

$$
\delta(b)=\tilde{e}(b)\left(b_{i+1}-b_{i}\right)^{s}+O\left(\left(b_{i+1}-b_{i}\right)^{s+1}\right), \quad b \in\left[b_{i}, b_{i+1}\right],
$$

where $\tilde{e}(b)$ is independent of $\Delta$. Then obviously the quantity $\mathcal{E}(b)$ satisfies $\mathcal{E}(b)-\delta(b)=O\left(h^{s+1}\right)$ and the error estimate is asymptotically correct. Our mesh adaptation is based on the equidistribution of the global error 


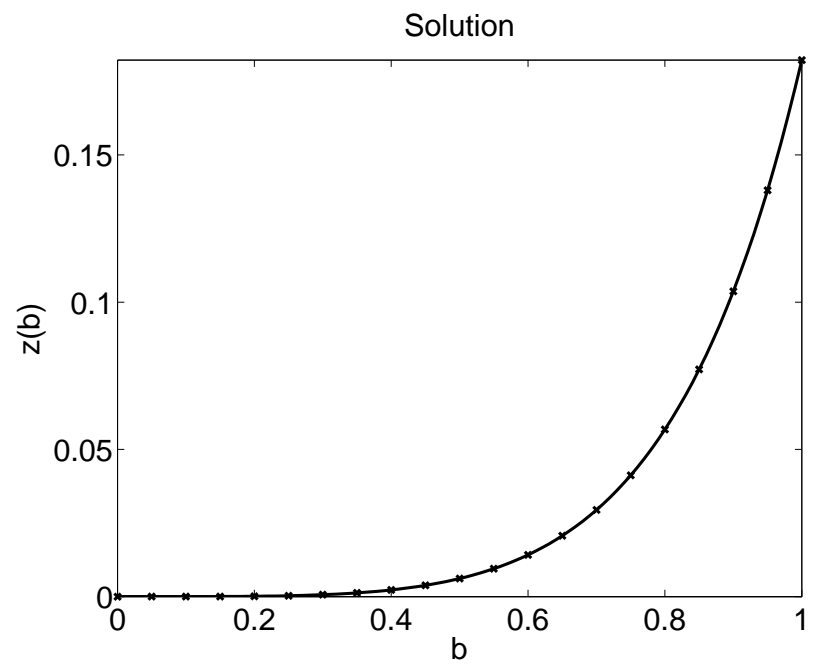

Figure 1: Solution of problem (21) for $\phi=1$ and $\zeta=1$ : values of analytical solution shown as crosses, numerical solution drawn as solid line.

of the numerical solution. Thus, we define a monitor function $\Theta(b):=\sqrt[s]{\mathcal{E}(b)} / h(b)$, where $h(b):=\left(b_{i+1}-b_{i}\right)$ for $b \in\left[b_{i}, b_{i+1}\right]$. Now, the mesh selection strategy aims at the equidistribution of

$$
\int_{\tilde{b}_{i}}^{\tilde{b}_{i+1}} \Theta(b) d b
$$

on the mesh consisting of points $\tilde{b}_{i}$ to be determined accordingly, where at the same time measures are taken to ensure that the variation of the stepsizes is restricted and tolerance requirements are satisfied with small computational effort. Details of the mesh selection algorithm and a proof of the fact that our strategy implies that the global error of the numerical solution is asymptotically equidistributed are given in [7].

We are now considering the following boundary value problem:

$\left(6(1-\phi) z(b)+(1+\phi) b z^{\prime}(b)\right) z^{\prime \prime}(b)-(15-9 \phi)\left(z^{\prime}(b)\right)^{2}-\frac{2(1-\phi) z(b) z^{\prime}(b)}{b}-\frac{4 \phi z^{\prime}(b)^{5 / 2}}{\sqrt{b}}=0, b \in(0,1]$,

$z(0)=0, \quad z^{\prime}(1)=\zeta$,

where $\zeta \geq 0$. Here, $\zeta$ are hypothetic values for the solution's first derivative at the right boundary, respectively. This way we can investigate the behavior of the solution for different values of $\zeta$ and $\phi$. Numerical computations show that the global behavior of the solution does not depend heavily on these two parameters, showing a strictly monotonous increase as a function of $b$. This is in a good agreement with the theoretical results.

We first consider the case $\phi=1$. Here, we know that $\gamma(1)=1$ and therefore $z^{\prime}(1)=1$ follows. Moreover, with Assumption 5 and $\phi=1$, the maximum ownership shares is given by $\gamma(b)=\frac{b}{2-b}$ and we can use (11) to determine the exact solution $z(b)$. We solve problem (21) numerically with $\zeta=1$ and compare the numerical values with the corresponding values of the exact solution, cf. Figure 1. All numerical calculations have been carried our with tolerance parameters for the absolute and relative errors set to $10^{-3}$. The numerical solution shows a good agreement with the analytical solution. 

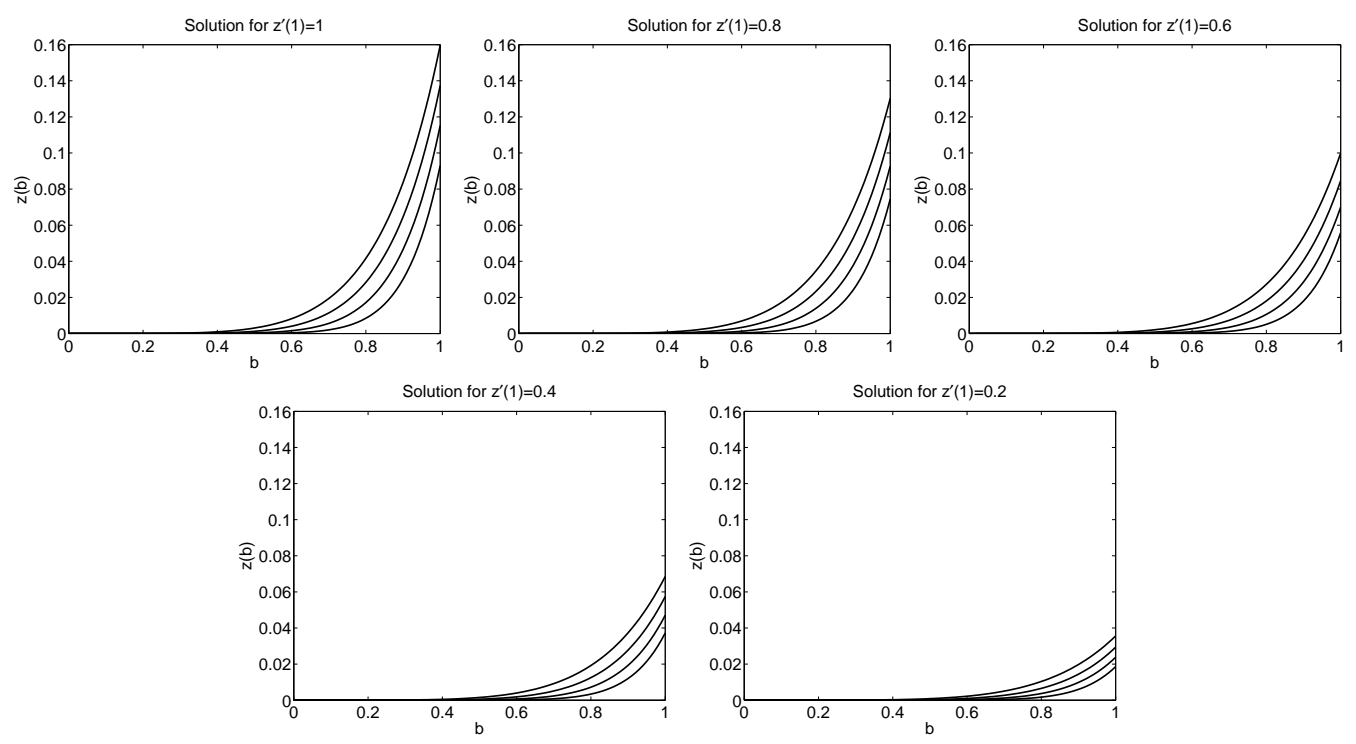

Figure 2: Solutions of problem (21) for varying $\zeta=1,0.8,0.6,0.4,0.2$. Each graph shows four curves related to $\phi=0.8$ (top), 0.6, 0.4, 0.2 (bottom).

We now consider problem (21) and vary the value of $\zeta$ and $\phi$. Figure 2 shows the numerical solutions for this problem, respectively. Naturally, the solutions vary but all graphs show in principle, the same solution behavior. All functions are strictly monotonously growing as a function of $b$ with growing derivatives, observed as steeper slopes towards the right end of the interval. Finally, Figure (3) shows the results for $\gamma(b)$ for the boundary value problem 21 .

\section{Conclusions}

From the above analysis and numerical experiments we may draw the following conclusions:

1. As in [38], the higher is the MNF's firm-specific advantage, the lower is the foreign ownership restriction. The idea is that for low values of firm-specific advantage, the cost of restricting the MNF's ownership share (efficiency effect) is not high. Thus, rent extraction motive is stronger. However, as the project's prospective rent (implied by firm-specific advantage of the MNF) increases, the cost of restricting the MNF's ownership also increases. Therefore, the host government assigns more shares to the MNF.

2. Unlike [38], we can see the effect of the host government's welfare choice over the optimal ownership restriction policy. Accordingly, the more the host government favors the local firm (the higher is the $\phi$ ), the more lenient the host government is towards the MNF. (Since in the numerical solution, we cannot change $\phi$ and $\zeta$ at the same time, this result is obtained under the assumed condition on the right boundary, namely on $z^{\prime}(1)$.) The reasoning is as follows: Under the specified model with a single tax on the whole JV, the government has to give information rent not only to the MNF but also to the LF. It is more willing to do so as the local firm's weight is higher in the host government's welfare. Since the information rent is a decreasing (increasing) function of the foreign ownership restrictions (maximum 


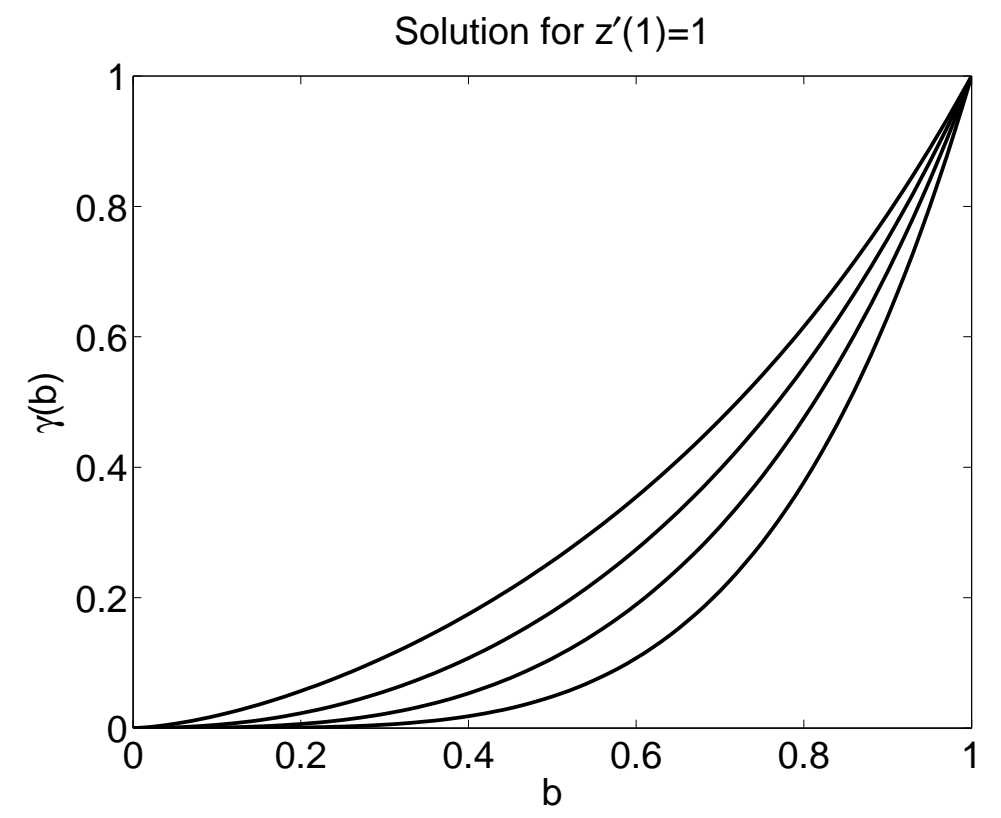

Figure 3: Solutions of problem (21) (right). Each graph shows four curves related to $\phi=0.8$ (top), 0.6, 0.4, 0.2 (bottom).

ownership shares the MNF can have), for a given firm-specific advantage, the host government assigns more shares to the MNF, increases the efficiency of the project, in effect, increasing the LF's profit. As the weight given to the LF in the welfare decreases, the host government is more interested in rent extraction than efficiency, thus assigns lower shares to the MNF for the same firm-specific advantage. We cannot see this relationship in [38] since no information rent is given to the LF due to separate taxation of JV partners.

3. The tax collected from the JV increases as the firm-specific advantage increases. The higher is the firm-specific advantage, the more shares are given the MNF and higher surplus is established. Therefore, the tax collected is also larger.

FDI has been recognized as one of the main driving factors shaping international economic relations between countries in the era of globalization characterized by rapid technological changes. The last decade has seen a pronounced increase in cross-border corporate ownership, as reflected in the rise in FDI. While the world inward stock of FDI rose only marginally as a share of GDP between 1980 and 1990, it has more than doubled in the last decade to $22 \%$ of world GDP in 2002, see [50].

Given the importance of FDI, countries praise its merits and look for different ways to attract FDI. One way to do so is designing appropriate FDI policy framework. However, this does not mean that host countries would follow policies that surrender power to multinational companies. Today, many countries still manage to attract large amounts of FDI while maintaining policy regimes that are not in the best interest of the multinational firms. For that reason, caution should be in place when evaluating the effects of increased FDI flows on host country policies. 
In this paper, under asymmetric information, we show that it is optimal for the host government to use foreign ownership restrictions. This restriction helps the host government to alleviate its information disadvantage and hence it is welfare-improving. We use a slightly different model than in [38] so that we restrict the host government in designing policy, i.e., it is not possible to collect tax from each JV partner separately. Under this specification, except for a simple case, it is not possible to derive an analytical solution. However, using a numerical approach, we are able to show that it is still optimal to employ foreign ownership restrictions and that the ownership restriction is lower, the higher the firm-specific advantage is. Furthermore, optimal ownership restriction for a given firm-specific advantage of the MNF is sensitive to the particular weight given to the local firm's profit in the host government's welfare function. This is an important improvement over the model in [38], since new specification enables us to refer to political factors, reflected via the weight given to the LF's profit, in determination of the ownership restrictions.

\section{Appendix}

Lemma 1 A mechanism $M$ is incentive compatible iff

$$
\frac{d \Pi^{M N F}(b)}{d b}=\alpha(b) \gamma(b)^{2} b
$$

almost everywhere, with $\Pi^{M N F}(b)=\max _{\widehat{b} \in[\underline{b}, \bar{b}]} \Pi^{M N F}(\widehat{b}, b)$ and the function $\alpha(b) \gamma(b)^{2}$ is non-decreasing.

Proof. Let the mechanism $M$ be incentive compatible, cf. (4). Let us assume type $b$ to choose an announcement $\widehat{b}$ to maximize $\Pi^{M N F}(\widehat{b}, b)$. If $\Pi^{M N F}(\widehat{b}, b)$ is differentiable at $(b, b)$ then two conditions need to be satisfied: From (4) the first derivative has to vanish,

$$
\left.\frac{\partial \Pi^{M N F}(\widehat{b}, b)}{\partial \widehat{b}}\right|_{\widehat{b}=b}=0,
$$

and the second derivative needs to be non-positive,

$$
\left.\frac{\partial^{2} \Pi^{M N F}(\widehat{b}, b)}{\partial \widehat{b}^{2}}\right|_{\widehat{b}=b} \leq 0 .
$$

Let $\Pi^{M N F}(b):=\max _{\widehat{b} \in[b, b]} \Pi^{M N F}(\widehat{b}, b)=\Pi^{M N F}(b, b)$. Then the total derivative of $\Pi^{M N F}(b)$ reads:

$$
\frac{d \Pi^{M N F}(b)}{d b}=\left.\frac{\partial \Pi^{M N F}(\widehat{b}, b)}{\partial \widehat{b}}\right|_{\widehat{b}=b}+\left.\frac{\partial \Pi^{M N F}(\widehat{b}, b)}{\partial b}\right|_{\widehat{b}=b}=\left.\frac{\partial \Pi^{M N F}(\widehat{b}, b)}{\partial b}\right|_{\widehat{b}=b}=\alpha(b) \gamma(b)^{2} b,
$$

due to (23) and (3). Integrating (25), we obtain

$$
\Pi^{M N F}(b)=\Pi^{M N F}(\underline{b})+\int_{\underline{b}}^{b} \alpha(\widetilde{b}) \gamma(\widetilde{b})^{2} \widetilde{b} d \widetilde{b}
$$

After differentiating (23), possibly except at a finite number of points, we have

$$
\left.\frac{\partial^{2} \Pi^{M N F}(\widehat{b}, b)}{\partial \widehat{b}^{2}}\right|_{\widehat{b}=b}+\left.\frac{\partial^{2} \Pi^{M N F}(\widehat{b}, b)}{\partial \widehat{b} \partial b}\right|_{\widehat{b}=b}=0
$$

Using (24) and (27), we conclude

$$
\left.\frac{\partial^{2} \Pi^{M N F}(\widehat{b}, b)}{\partial \widehat{b} \partial b}\right|_{\widehat{b}=b} \geqslant 0
$$


and therefore $\alpha(b) \gamma(b)^{2}$ is non-decreasing in $b \in[\underline{b}, \bar{b}]$.

We now show that (22) and the monotonicity of $\alpha(b) \gamma(b)^{2}$ are sufficient for global incentive compatibility on $[\underline{b}, \bar{b}]$. Suppose type $b$ reports that its type is $\widehat{b}$. Then, using (3) and (26), its profit is given by:

$$
\begin{aligned}
\Pi^{M N F}(\widehat{b}, b) & =\Pi^{M N F}(\widehat{b})+\frac{\alpha(\widehat{b}) \gamma(\widehat{b})^{2}\left(b^{2}-\widehat{b}^{2}\right)}{2} \\
& =\Pi^{M N F}(b)-\int_{\widehat{b}}^{b} \alpha(\widetilde{b}) \gamma(\widetilde{b})^{2} \widetilde{b} d \widetilde{b}+\frac{\alpha(\widehat{b}) \gamma(\widehat{b})^{2}\left(b^{2}-\widehat{b}^{2}\right)}{2} \\
& =\Pi^{M N F}(b)+\int_{\widehat{b}}^{b}\left(\alpha(\widehat{b}) \gamma(\widehat{b})^{2}-\alpha(\widetilde{b}) \gamma(\widetilde{b})^{2}\right) \widetilde{b} d \widetilde{b}
\end{aligned}
$$

If $b>\widehat{b}$, then the integrand is non-positive (since $\widehat{b}<\widetilde{b}$ ) by (28), and so $\Pi^{M N F}(\widehat{b}, b) \leq \Pi^{M N F}(b)$. If $b<\widehat{b}$, then the integrand is non-negative but the integral is non-positive (since the direction of integration is now backwards), and therefore, $\Pi^{M N F}(\widehat{b}, b) \leq \Pi^{M N F}(b)$ still holds.

Lemma 2 In any feasible mechanism, the welfare function of the host government is given by

$$
W=\int_{\underline{b}}^{\bar{b}}\left(\pi^{M N F}+\left(\frac{1+\phi(1-\gamma(b))}{2} \gamma(b) b^{2}\right)-\frac{1-\phi(1-\gamma(b))}{\gamma(b)}\left(\int_{\underline{b}}^{b} \gamma^{2}(\widetilde{b}) \widetilde{b} \widetilde{d b}\right)\right) d F(b) .
$$

Proof. Let $\phi=\frac{\phi_{2}}{\phi_{1}} \leq 1$. Then, using (7), the host government's welfare can be written as

$$
\begin{aligned}
W= & \int_{\underline{b}}^{\bar{b}}\left((1-\alpha(b)) T^{L F}(b)+\alpha(b) T(b)\right) d F(b) \\
& +\phi \int_{\underline{b}}^{\bar{b}}\left((1-\alpha(b))\left(\pi^{L F}-T^{L F}(b)\right)\right. \\
& \left.+\alpha(b)(1-\gamma(b))\left(\pi^{M N F}+\gamma(b) b^{2}-T^{J V}(b)\right)\right) d F(b) .
\end{aligned}
$$

Note that when the MNF is not allowed to operate, there is nothing unknown about the profit of the LF. Since it is assumed that $\phi_{1} \geq \phi_{2}$, given assumption 2, the host government will collect all of the LF's profit as a tax revenue if LF operates by itself. Also, if $\phi_{1}=\phi_{2}$, the host government is indifferent between its tax revenue and the LF's profit. As a convention, we assume that the host government collects all of the LF's profit in this case. This assumption will not affect any further result. Thus, we have

$$
T^{L F}(b)=T^{L F}=\pi^{L F} .
$$

In addition, from the definition of $\Pi^{M N F}(b)$ in (3) we conclude

$$
\alpha(b) \gamma(b) T^{J V}(b)=\alpha(b) \gamma(b)\left(\pi^{M N F}+\gamma(b) b^{2}\right)-\alpha(b) \frac{(\gamma(b) b)^{2}}{2}-\Pi^{M N F}(b) .
$$


We now substitute (26) into the above equation and obtain

$$
\begin{aligned}
T^{J V}(b)= & \left(\pi^{M N F}+\gamma(b) b^{2}\right)-\frac{\gamma(b) b^{2}}{2} \\
& -\frac{1}{\alpha(b) \gamma(b)}\left(\int_{\underline{b}}^{b} \alpha(\widetilde{b}) \gamma(\widetilde{b})^{2} \widetilde{b} \widetilde{d}+\Pi^{M N F}(\underline{b})\right) .
\end{aligned}
$$

Substitution of (31) and (32) into (30) yields

$$
\begin{aligned}
W= & \int_{\underline{b}}^{\bar{b}}\left((1-\alpha(b)) \pi^{L F}+\alpha(b) \pi^{M N F}\right) d F(b)+ \\
& \int_{\underline{b}}^{\bar{b}} \alpha(b)\left(\frac{1+\phi(1-\gamma(b))}{2} \gamma(b) b^{2}\right)-\frac{1-\phi(1-\gamma(b))}{\gamma(b)} \int_{\underline{b}}^{b} \alpha(\widetilde{b}) \gamma^{2}(\widetilde{b}) \tilde{b} d \tilde{b} d F(b)- \\
& \Pi^{M N F}(\underline{b}) \int_{\underline{b}}^{\bar{b}} \frac{1-\phi(1-\gamma(b))}{\gamma(b)} d F(b) .
\end{aligned}
$$

The last term is negative since the integrand is positive; $\phi \leq 1$ and $0 \leq \gamma(b) \leq 1$, hence $1-\phi(1-\gamma(b)) \geqslant 0$. Thus, it is optimal to set $\Pi^{M N F}(\underline{b})=0$. As a result we have,

$$
\begin{aligned}
W= & \int_{\underline{b}}^{\bar{b}}\left[(1-\alpha(b)) \pi^{L F}+\alpha(b) \pi^{M N F}\right] d F(b)+ \\
& \int_{\underline{b}}^{\bar{b}} \alpha(b)\left(\frac{1+\phi(1-\gamma(b))}{2} \gamma(b) b^{2}\right)-\frac{1-\phi(1-\gamma(b))}{\gamma(b)}\left(\int_{\underline{b}}^{b} \alpha(\widetilde{b}) \gamma^{2}(\widetilde{b}) \widetilde{b} \widetilde{b}\right) d F(b) .
\end{aligned}
$$

Given assumption $5, \alpha(b)=1 \forall b$, the final form for the welfare of the host government reads, cf. (33):

$$
W=\int_{\underline{b}}^{\bar{b}}\left(\pi^{M N F}+\left(\frac{1+\phi(1-\gamma(b))}{2} \gamma(b) b^{2}\right)-\frac{1-\phi(1-\gamma(b))}{\gamma(b)}\left(\int_{\underline{b}}^{b} \gamma^{2}(\widetilde{b}) \widetilde{b} d \tilde{b}\right)\right) d F(b)
$$

which completes the proof.

Proposition 3. Let $\phi=1$ and let Assumptions $1-5$ hold. Then the optimal mechanism is specified by the following values:

$$
\begin{aligned}
T^{L F}(b) & =T^{L F}=\pi^{L F} \\
T^{J V}(b) & =\pi^{M N F}+\frac{\gamma(b) b^{2}}{2}-\frac{1}{\alpha(b) \gamma(b)} \int_{\underline{b}}^{b} \alpha(\widetilde{b}) \gamma(\widetilde{b})^{2} \widetilde{b} d \widetilde{b} \\
\gamma(b) & =\frac{b}{2\left(\frac{1-F(b)}{f(b)}\right)+b} .
\end{aligned}
$$


Proof: Note that the value for $T^{L F}(b)$ have been already determined in the proof of Lemma 2. One can easily obtain $T^{J V}(b)$ from (32) and (36). Therefore, it only remains to show that the expression for $\gamma(b)$ is correct.

When $\phi=1$, equation (29) becomes

$$
W=\int_{\underline{b}}^{\bar{b}}\left(\pi^{M N F}+\left(\frac{2-\gamma(b)}{2} \gamma(b) b^{2}\right)-\left(\int_{\underline{b}}^{b} \gamma^{2}(\tilde{b}) \tilde{b} d \tilde{b}\right)\right) d F(b) .
$$

We now integrate last term in (34) by parts,

$$
\begin{aligned}
\int_{\underline{b}}^{\bar{b}}\left(\int_{\underline{b}}^{b} \gamma^{2}(\widetilde{b}) \widetilde{b} \widetilde{d b}\right) d F(b) & =\int_{\underline{b}}^{\bar{b}} \gamma^{2}(\widetilde{b}) \widetilde{b} d \underbrace{\widetilde{b}}_{=1} \underbrace{(\bar{b})}_{\underline{b}}-\int_{\underline{b}}^{\bar{b}} F(\widetilde{b}) \gamma^{2}(\widetilde{b}) \widetilde{b} \widetilde{b} \\
& =\int_{\underline{b}}^{\bar{b}} \gamma^{2}(b) b(1-F(b)) d b,
\end{aligned}
$$

and substitute back into (34),

$$
W=\int_{\underline{b}}^{\bar{b}}\left(\pi^{M N F}+\frac{2-\gamma(b)}{2} \gamma(b) b^{2}-\frac{1-F(b)}{f(b)} \gamma^{2}(b) b\right) f(b) d b .=: \int_{\underline{b}}^{\bar{b}} \widetilde{W}(b, \gamma(b)) d b .
$$

We now maximize $W$ with respect to $\gamma$ using calculus of variations. Since $\widetilde{W}$ does not depend on $\gamma^{\prime}(b)$ the Euler-Lagrange equation reads:

$$
\frac{\partial \widetilde{W}}{\partial \gamma}=0 \Rightarrow\left(b^{2}-\gamma(b) b^{2}-\frac{1-F(b)}{f(b)} 2 \gamma(b) b\right) f(b)=0
$$

which results in

$$
\gamma(b)=\frac{b}{2\left(\frac{1-F(b)}{f(b)}\right)+b} .
$$

Note that the second derivative of $W$ with respect to $\gamma$ is non-positive, and therefore, at $\gamma$ given in (36), $W$ assumes its maximum.

Proposition 4 Let $z^{\prime \prime}(\xi) \geq 0$. Then $\lambda_{1,2} \in \mathbb{R}$ and $\lambda_{1}>0, \quad \lambda_{2}<0$.

Proof: It follows from (16) that $z^{\prime \prime}(\xi) \geq 0$ holds. Let

$$
\lambda_{1}:=X+Y, \quad \lambda_{2}:=X-Y,
$$

where

$$
X:=\frac{1}{2}+\frac{5\left(3-2 \phi+\phi \sqrt{z^{\prime \prime}(\xi)}\right)}{2(2-\phi)}
$$

and

$$
Y:=\sqrt{\underbrace{\frac{353-384 \phi+140 \phi^{2}+190 \phi \sqrt{z^{\prime \prime}(\xi)}-120 \phi^{2} \sqrt{z^{\prime \prime}(\xi)}+25 \phi^{2} z^{\prime \prime}(\xi)}{4(2-\phi)^{2}}}_{=: \widetilde{Y}} .}
$$


We first show that $\tilde{Y}>0$, which means that $Y \in \mathbb{R}$. Obviously, the denominator of $\tilde{Y}$ is positive since $\phi \in[0,1)$. Thus, it remains to show that

$$
353-384 \phi+140 \phi^{2}+190 \phi \sqrt{z^{\prime \prime}(\xi)}-120 \phi^{2} \sqrt{z^{\prime \prime}(\xi)}+25 \phi^{2} z^{\prime \prime}(\xi) \geq 0 .
$$

We split the above expression into

$$
\widetilde{Y}_{1}:=190 \phi \sqrt{z^{\prime \prime}(\xi)}-120 \phi^{2} \sqrt{z^{\prime \prime}(\xi)}
$$

and

$$
\widetilde{Y}_{2}:=353-384 \phi+140 \phi^{2}+25 \phi^{2} z^{\prime \prime}(\xi)
$$

Clearly, $\widetilde{Y}_{1} \geq 0$ since $\phi \in[0,1)$. For $\phi \leq 0.5$, it follows immediately that $\widetilde{Y}_{2}>0$. For $\phi \in(0.5,1)$ we note that $354-384 \phi>-31$ and $140 \phi^{2}>35$ and therefore again $\widetilde{Y}_{2}>0$. Consequently, $Y \in \mathbb{R}$ is positive. Moreover, $X>0$. It is now sufficient to show that $X<Y$ to conclude that $\lambda_{1}>0$ and $\lambda_{2}<0$. We first write $X$ in a form corresponding to the representation of $Y$,

$$
X=\sqrt{\frac{289-374 \phi+121 \phi^{2}+170 \phi \sqrt{z^{\prime \prime}(\xi)}-110 \phi^{2} \sqrt{z^{\prime \prime}(\xi)}+25 \phi^{2} z^{\prime \prime}(\xi)}{4(2-\phi)^{2}}} .
$$

Now we only have to compare the numerators of $X$ and $Y$ and show that

$$
\begin{array}{r}
353-384 \phi+140 \phi^{2}+190 \phi \sqrt{z^{\prime \prime}(\xi)}-120 \phi^{2} \sqrt{z^{\prime \prime}(\xi)}+25 \phi^{2} z^{\prime \prime}(\xi)> \\
289-374 \phi+121 \phi^{2}+170 \phi \sqrt{z^{\prime \prime}(\xi)}-110 \phi^{2} \sqrt{z^{\prime \prime}(\xi)}+25 \phi^{2} z^{\prime \prime}(\xi),
\end{array}
$$

which is equivalent to

$$
64-10 \phi+19 \phi^{2}+20 \phi \sqrt{z^{\prime \prime}(\xi)}-10 \phi^{2} \sqrt{z^{\prime \prime}(\xi)}>0 .
$$

Again, due to $\phi \in[0,1)$ the last inequality holds and this completes the proof.

\section{References}

[1] U. Ascher, R. M. M. MattheiJ, and R. D. Russell. Numerical solution of boundary value problems for ordinary differential equations, Prentice-Hall: New York, USA (1988).

[2] E. Asiedu, and H. S. Esfahani. Ownership Structure in Foreign Direct Investment Projects, Review of Economics and Statistics 83(4) (2001), 647-662.

[3] W. Auzinger, G, Kneisl, O. Koch, and E. Weinmüller. A Solution Routine for Singular Boundary Value Problems, Inst. for Appl. Math. and Numer. Anal., Techn. Rep. ANUM Preprint Nr. 1/02 (2002). Available at http://www.math.tuwien.ac.at/inst115/preprints.htm.

[4] W. Auzinger, O. Koch, and E. Weinmüller. Efficient collocation schemes for singular boundary value problems, Numer. Algorithms 31(1-4) (2002), 5-25.

[5] W. Auzinger, O. Koch, and E. Weinmüller. Analysis of a New Error Estimate for Collocation Methods Applied to Singular Boundary Value Problems, SIAM J. Numer. Anal. 42(6) (2005), 23662386 .

[6] W. Auzinger, G. Kneisl, O. Koch, and E. Weinmüller. A collocation code for boundary value problems in ordinary differential equations, Numer. Algorithms 33(1-4) (2003), 27-39.

[7] W. Auzinger, O. Koch, and E. Weinmüller. Efficient mesh selection for collocation methods applied to singular BVPs, J. Comput. Appl. Math. 180(1) (2005), 213-227. 
[8] M. Bagnoli, and T. Bergstrom. Log-Concave Probability and Its Applications, Economic Theory 26(2) (2005), 445-469.

[9] D. Baron, and R. Myerson. Regulating a Monopolist with Unknown Cost, Econometrica 50(4) (1982), 911-930.

[10] M. Blomström, And E. Wolff. Multinational Corporations and Productivity Convergence in Mexico, in W. Baumol, R. Nelson, and E. Wolff (Eds.), Convergence of Productivity: Cross-National Studies and Historical Evidence, Oxford University Press: Oxford, UK (1994).

[11] E. Borensztein, J. De Gregorio, and J-W. Lee. How Does Foreign Direct Investment Affect Economic Growth?, Journal of International Economics 45(1) (1998), 115-135.

[12] C. J. Budd, O. Koch, and E. Weinmüller. Self-similar blow-up in nonlinear PDEs. AURORA TR-2004-15, Inst. for Anal. and Sci. Comput., Vienna Univ. of Technology, Austria (2004). Available at http://www.vcpc.univie.ac.at/aurora/publications/.

[13] R. E. Caves. Multinational Enterprise and Economic Analysis, Cambridge University Press: Cambridge, UK (1982).

[14] P. G. Cerny. Globalization and The Changing Logic of Collective Action, International Organization 49(4) (1995), 595-625.

[15] F. Contractor. Government Policies and Foreign Direct Investment, United Nations Center on Transnational Corporations (UNCTC) Current Studies, Series A, No 17, United Nations Publication: New York, USA (1991).

[16] S. P. Das, and S. Katayama. International Joint Venture and Host-Country Policies, Japanese Economic Review 54(4) (2003), 381-394.

[17] P. Dasgupta, P. Hammond, and E. Maskin. The Implementation of Social Choice Rules: Some General Results on Incentive Compatibility, Review of Economic Studies 46(2) (1979), 185-216.

[18] S. Dasgupta, and K. Sengupta. Optimal Regulation of MNEs and Government Revenues, Journal of Public Economics 58(2) (1995), 215-234.

[19] F. R. De Hoog, And R. Weiss. Collocation Methods for Singular Boundary Value Problems, SIAM J. Numer. Anal. 15(1) (1978), 198-217.

[20] F. R. De Hoog, And R. Weiss. Difference Methods for Boundary Value Problems With a Singularity of the First Kind, SIAM J. Numer. Anal. 13(5) (1976), 775-813.

[21] F. R. De Hoog, and R. Weiss. The Application of Runge-Kutta Schemes to Singular Initial Value Problems, Math. Comp. 44(169) (1985), 93-103.

[22] Department of Business Development, Ministry of Commerce, http://www.dbd.go.th/eng/law/fba_e1999.phtml.

[23] K. M. Diaw. Ownership Restrictions, Tax Competition and Transfer Pricing Policy, Discussion Paper No 3, Center for Economic Research, Tilburg University, Netherlands (2004).

[24] M. E. Doms, And J. B. Jensen. Comparing Wages, Skills, and Productivity between Domestically and Foreign-Owned Manufacturing Establishments in the United States, in R. E. Baldwin, R. E. Lipsey, and J. D. Richardson (Eds.), Geography and Ownership as Bases for Economic Accounting, Studies in Income and Wealth, 59, University of Chicago Press: Chicago, USA (1998). 
[25] C. Doyle, and S. van-Wijnbergen. Taxation of Foreign Multinationals: A Sequential Bargaining Approach to Tax Holidays, International Tax and Public Finance 1(3) (1994), 211-225.

[26] J. H. Dunning. Multinational Enterprises and the Global Economy, Adison-Wesley Publishing: Workingham, UK (1993).

[27] R. E. Falvey, and H. O. Fried. National Ownership Requirements and Transfer Pricing, Journal of Development Economics 24(2) (1986), 249-254.

[28] Financial Times, 'Thailand to end curbs on foreign ownership', August 20, 1998.

[29] S. Globerman, J. Ries, and I. Vertinsky. The Economic Performance of Foreign Affiliates in Canada, Canadian Journal of Economics 27(1) (1994), 143-156.

[30] S. Golub. Measures of Restrictions on Inward Foreign Direct Investment for OECD Countries, OECD Economics Department Working Papers No 357 (2003).

[31] S. Golub and t. koyama. OECD's FDI Regulatory Restrictiveness Index: Revision and Extension to More Economies, OECD Economics Department Working Papers No 525 (2006).

[32] S. J. Grossman, and O. D. Hart. The Costs and Benefits of Ownership: A Theory of Vertical and Lateral Integration, Journal of Political Economy 94(4) (1986), 691-719.

[33] M. Haddad, and A. Harrison. Are There Positive Spillovers from Direct Foreign Investment?: Evidence from Panel Data for Morocco, Journal of Development Economics 42(1) (1993), 51-74.

[34] S. Haggard. Pathways from The Periphery, Cornell University Press: Ithaca, USA (1990).

[35] O. Hart. Firms, Contracts and Financial Structure, Clarendon Press: Oxford, UK (1995).

[36] O. Hart, and J. Moore. Property Rights and Nature of the Firm, Journal of Political Economy 98(6) (1990), 1119-1158.

[37] E. Helpman, M. J. Melitz, and S. R. Yeaple. Export versus FDI with Heterogeneous Firms, American Economic Review 94(1) (2004), 300-316.

[38] B. Karabay. Foreign Direct Investment and Host Country Policies: A Rationale for Using Ownership Restrictions, Working Paper, University of Virginia, USA (2005).

[39] H. Katrak. Multinational Firms' Global Strategies, Host Country Indigenization of Ownership and Welfare, Journal of Development Economics 13(3) (1983), 331-348.

[40] G. Kitzhofer. Numerical treatment of implicit singular BVPs. Ph.D. Thesis, Inst. for Anal. and Sci. Comput., Vienna Univ. of Technology, Austria (2005). In preparation.

[41] G. Kitzhofer, O. Koch, and E. Weinmüller. Collocation methods for the computation of bubbletype solutions of a singular boundary value problem in hydrodynamics, J. Sci. Comp. To appear. Available at http://www.math.tuwien.ac.at/ ${ }^{2}$ wa.

[42] E. Kocenda, and J. Svejnar. Ownership and Firm Performance After Large-Scale Privatization, CEPR Discussion Paper No 4143 (2003).

[43] O. Koch, Asymptotically Correct Error Estimation for Collocation Methods Applied to Singular Boundary Value Problems, Numer. Math. 101(1) (2005), 143-164. 
[44] A. Kokko, R. Tansini, and M. Zejan. Local Technological Capability and Spillovers from FDI in the Uruguayan Manufacturing Sector, Journal of Development Studies 32(4) (1996), 602-611.

[45] A. Kokko, R. Tansini, and M. Zejan. Trade Regimes and spillover effects of FDI: evidence from Uruguay, Weltwirtschaftliches Archiv 137(1) (2001), 124-149.

[46] J. J. Laffont, and J. Tirole. Using Cost Observation to Regulate Firms, Journal of Political Economy 94(3) (1986), 614-641.

[47] A. MukherJeE. Foreign Market Entry and Host-Country Welfare: A Theoretical Analysis, GEP Research Paper No 2003/08, University of Nottingham (2003).

[48] R. B. Myerson. Incentive Compatibility and The Bargaining Problem, Econometrica 47(1) (1979), $61-74$.

[49] L. Oxelheim, and P. Ghauri. The Race for FDI in the European Union, in L. Oxelheim and P. Ghauri (Eds.), European Union and The Race for Foreign Direct Investment in Europe, International Business and Management Series, Elsevier: Oxford, UK (2004).

[50] A. Riess, and K. Uppenberg. Determinants and Growth Effects of Foreign Direct Investment, European Investment Bank (EIB) Papers 9(1) (2004).

[51] M. Schnitzer. Expropriation and Control Rights: A Dynamic Model of Foreign Direct Investment, International Journal of Industrial Organization 17(8) (1999), 1113-1137.

[52] F. Sృ̈̈нolm. Technology Gap, Competition and Spillovers from Direct Foreign Investment: Evidence from Establishment Data, Journal of Development Studies 36(1) (1999), 53-73.

[53] J. M. Stopford, and S. Strange. Rival States, Rival Firm: Competition for World Market Shares, Cambridge University Press: Cambridge, UK (1991).

[54] J. Svejnar, And S. C. Smith. The Economics of Joint Ventures in Less Developed Countries, Quarterly Journal of Economics 99(1) (1984), 149-168.

[55] A. Walter. Globalization and Policy Convergence: The Case of Direct Investment Rules, in R. A. Higgott, G. R. D. Underhill, and A. Bieler (Eds.), Non-state Actors and Authority in the Global System, Routledge: Warwick, UK (1999).

[56] E. Weinmüller. On the Boundary Value Problems for Systems of Ordinary Differential Equations with a Singularity of the First Kind, SIAM J. Numer. Anal. 15(2) (1984), 287 - 307.

[57] E. Weinmüller. On the Numerical Solution of Singular Boundary Value Problems of Second Order by a Difference Method, Mathematics of Computation 46(173) (1986), 93 - 117.

[58] E. Weinmüller. Collocation for Singular Boundary Value Problems of Second Order, SIAM J. Numer. Anal. 23(5) (1986), 1062-1095. 